\title{
DESIGN AND IMPLEMENTATION OF AN INTELLIGENT GAS CYLINDER VALVE REgULATING SYSTEM USING SOLENOID
}

\author{
Ebenezer Narh Odonkor ${ }^{1}$, Willie K. Ofosu ${ }^{2}$, Patrick Appiah ${ }^{3}$ and Daniel Kubawe ${ }^{4}$ \\ ${ }^{1}$ Faculty of Engineering, Department of Electrical and Electronics Engineering, Takoradi \\ Technical University, Takoradi - Ghana. \\ Email: ebenezer.narh.odonkor@tpoly.edu.gh. \\ ${ }^{2}$ Penn State Wilkes-Barre 1269 Old 115 Dallas, PA 18612. \\ Email:wko1@psu.edu. \\ ${ }^{3}$ Electrical and Electronic Department, Methodist Technical Institute, Kumasi-Ghana. \\ Email: patricktee1982@gmail.com. \\ ${ }^{4}$ Alang Junior High School, Chuchuga, Upper East Region, Ghana. \\ Email: Kubawedaniel@gmail.com.
}

\begin{abstract}
Developed and developing nations like Ghana frequently experience fire outbreaks which area major problem across the globe. Some causes of such fire outbreaks are due to Leakage gas, electrical fault. Some attendant problems are accidents, loss of life and damage to properties. National fire service stations may be the answer to these conditions in Ghana but few stations are built in some specific places in Ghana. This paper proposed a design and implementation of an intelligent gas stove valve regulating system using Solenoid Valve. Temperature sensor, gas sensor and 555 Timer were used. The proposed system will detect time setting for cooking and cut off gas flow automatically to the stove when food is cooked, gas leakage is detected and when surround temperature is above the threshold. Proteus software is used for designing and simulating of the circuit. Programming was done using the Arduino software. Microcontroller ATMEGA 328 serves as the heart of the design. A Liquid Crystal Display (LCD) is used to show the condition of the stove. In addition, a buzzer is used to sound an alarm when food is cooked. The system has facilities to shut-off gas stove regulator automatically when food is cooked, gas leakage is detected or when a high temperature is detected.
\end{abstract}

\section{KEYWORDS}

Microcontroller, Gas Sensor, Temperature Sensor, LCD, Solenoid valve, and 555 Timer.

\section{INTRODUCTION}

Liquefied petroleum gas (LPG) produces less soot as well as smoke, hence its usage is increasing in developing countries like Ghana. LPG is a flammable mixture of hydrocarbon gases used as fuel for heating appliances, cooking equipment, and vehicles. Gas pipe lines (tubes) are used as the transmission medium for transmitting LPG to gas stove burners used at home, hotels, restaurant, and industries. Mishandling of LPG at these places can result in fire outbreak, which can be fatal to property and injuries or even deaths to people [1].The focus on homes, offices, industries, hotels, restaurant and other facility safety where LPG fire is used is on the rise as standard of living improves, hence the demand of the protection of gas stove usage to prevent fire outbreaks [2]. 
A study conducted by [3] on fire outbreaks trend in Ghana and its prevention shows that,10,355 domestic fire outbreak case was recorded in Ghana between 2007 to 2013 which represent $41 \%$ of the total fire outbreak during that period. In their study, some areas like domestic, industrial, vehicular, institutional, electrical, commercial, bush and others are identified to be prone to fire outbreaks. The researchers recorded that, 25,623 fire case was established in such areas in Ghana between 2007 and 2013 with properties and lives being loss causing billions of Ghana cedis. Again, the Ghana National Fire Service (GNFS) has recorded 5,531 fire outbreaks across the country in 2018 compared with the 2017 total of 4,544 cases [1].

Leakages of gas are the most fatal accident that can create serious problems in household and other areas where PLG is used. When it is not handled with care, leakage of Gas can lead to various accidents resulting in financial loss and loss of human lives. In light of this, [4] [7] proposed a design and implementation of a kitchen gas leakage detection and automatic gas shut off system which were used as a first aid to notify occupants with an alarm when gas leakage is detected to reduce the highly harmful effect nature of leakage gas of humanity and properties. In a study of [5], they also proposed a movable gas tanker leakage detection and response system capable of shutting off gas supply through the gas valve with an alarm to create an alert that there is a leakage of gas using wireless sensor network based on embedded systems.

Over the years, many lives and properties are loss through fire caused by gas causing the countries (Ghana) millions Ghana cedis of money due to in adequate of monitoring systems for gas cylinders at home, hence [6] developed an efficient LPG leakage detection and prevention system for home safety using artificial intelligence systems and machine learning. Their system can detect the level of gas in a cylinder or any leakage and send SMS to the user for prompt actions to be taken to minimize fire outbreaks at homes.

Some researchers also conducted a study into intelligent gas booking and leakage system using wireless sensor networks to notify owners of leakage or emptiness (level or weight of gas) of the cylinder through a wireless system to enable the gas users to book and refill the cylinder and also to avert any fire outbreak due to leakage of LPG [8] [9]. A study that uses GSM technology of detection and alerting gas users about the leakage of gas through short messages (SMS) and closing of cylinder head to avert further leakage were proposed [10] [12].

These researchers [11] also came out with a development of a liquefied petroleum gas leakage detector, level indicator and automatic shutdown system. Their system was implemented using a resistive force sensor, MQ6 gas sensor and Arduino mega. The MQ6 sensor was used to detect leakage of gases at homes, restaurants and hotels. Even though their system can shut-off the cylinder valve, it cannot monitor cooking foods. It is obviously clear that some researches have gone into the gas leakage detection and alerting systems through SMS, alarm, closing of cylinder valves, but a few researches have gone into a cooking monitoring system to turn off gas valve when food is done.

Again, the above researches revealed that, mishandle of gas can cause some countries, millions of monies, for this reason, the need of developing an intelligent monitoring and regulation gas cylinder valve system. This necessitates the proposed systems that can monitor cooking and turns off gas cylinder valve when food is cooked, and also capable of detecting and given an alert of gas leakage, and temperature above the threshold of the cylinder. In this paper, a proposed design and implementation of an intelligent gas cylinder valve regulating system using solenoid valve that will provide homes, market places, restaurants, industry safety when cooking using gas stove or when gas leakage and high temperature of gas cylinder is detected to avert any fire outbreak that will caused by the use of LPG. 


\section{Design Methodology}

The system is designed and simulated using Proteus software with the programming done using Arduino programming software. The proposed system uses a solenoid valve in addition with a timer to control the flow of LPG from the cylinder to the gas stove when cooking. A temperature sensor and gas sensor are added to the proposed system to monitor surrounding temperature and gas leakage. An alarm is activated when gas leakage is detected, and temperature surroundings a gas cylinder is beyond the set point. The system is able to shut-off the cylinder valve to prevent fire outbreaks when cooking. To reduce or prevent increasing gas concentration when cooking, the supply of gas to the gas stove burner must be shut-off when set time for cooking is up or leaking gas and high temperature is detected. An LCD display is added to the system to alert the owner of the status of the gas cooker system. The prototype is tested in a real-time basis.

\section{BLOCK DIAGRAM}

The block diagram in Figure1 below shows how the arrangement of components of the proposed intelligent gas valve regulator and temperature monitoring system with an automatic gas shut-off valve. The system consists of a microcontroller, power supply, LCD display, gas sensor, temperature sensor, buzzer, timer, relay driver, gas cylinder, stove and a solenoid valve controller.

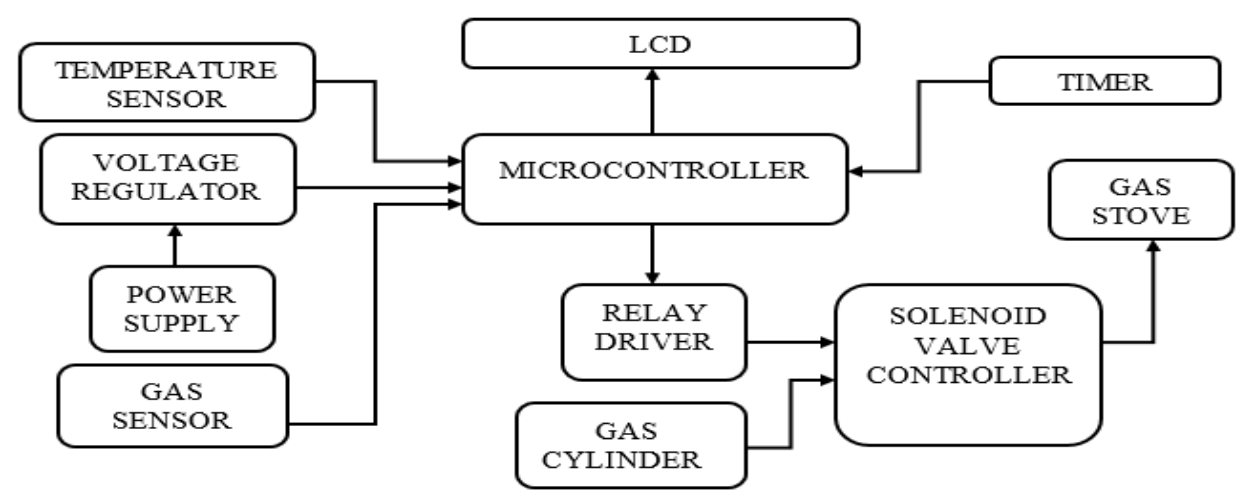

Figure 1: The Block Diagram of an intelligent Gas Cylinder Valve Regulating System.

\section{DESCRIPTION OF BLOCK DiAgRAM}

The circuit is powered by a 12 Volt battery. This voltage is fed into a voltage regulator (7805) through pin VI. This reduces the voltage from 12VDC to 5VDC to power the microcontroller ATMEGA 328. The microcontroller is programmed to receive an input from the temperature sensor, gas sensor and the timer. The temperature sensor is used to detect or sense changes in surrounding temperature of gas cylinder. When the temperature signal from the sensor is more than the threshold voltage, the temperature sensor sends a signal to the microcontroller. Signals from the gas and temperature sensor is sent to microcontroller to provide an output with respect to the input signal. This output(s) is display on the liquid crystal display (LCD) to indicate the status of the gas stove. When the preset timer for cooking is reached, the microcontroller sends a signal again to the relay driver block to latch the solenoid. The solenoid valve remains open to allow gas to flow from the gas cylinder through solenoid valve controller to the gas stove (burner) under normal condition. When the threshold time for cooking is reached, the microcontroller sends a command to the relay and to de-energize the solenoid coil, thereby causing the shut-off valve of the solenoid to close. 
The relay is energized to break the gas circuit for receiving gas supplies from the cylinder when high surrounding temperature or cooking time setting (input time) is reached.

\section{Circuit Design}

The circuit diagram in Figure 2 below shows detail linking together and arrangement of components of the proposed intelligent gas valve regulator and temperature monitoring system with an automatic gas shut-off valve system.

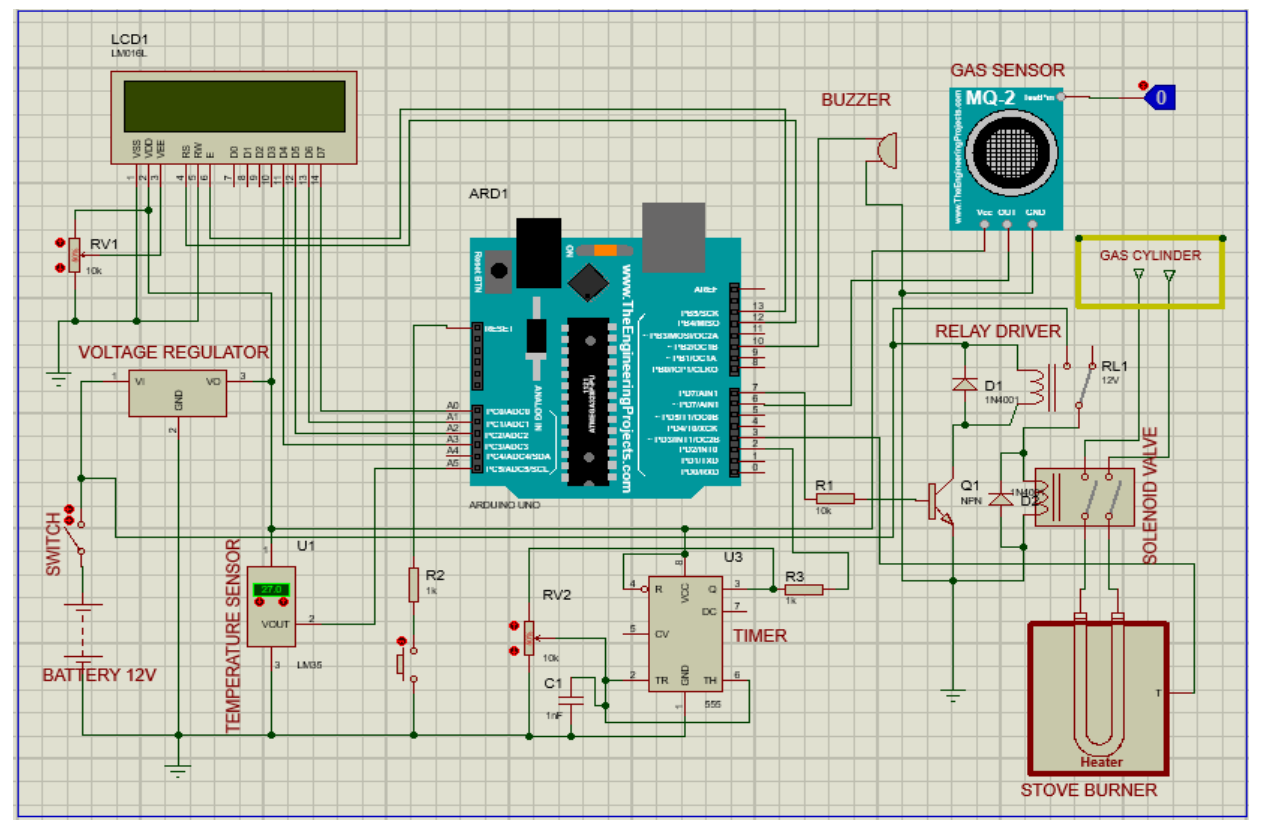

figure 2: The circuit diagram of an intelligent gas cylinder valve regulating system.

The entire circuitry powered using a 12 VDC battery. Voltage regulator (7805) terminal 1is connected to the temperature sensor terminal, VDD terminal of the liquid crystal display (LCD) and timer pin 4 and 8, gas sensor terminal VCC is also connected to the output terminal 3 of 7805 respectively with terminal 2 of the 7805 connected to ground. Temperature sensor (LM35) output terminal 2 is connected to A0 terminal on the Arduino board to monitor surrounding temperature. The timer and the relay driver are connected to the output of the switch to supply 12VDC. Terminal 2 of the gas sensor is connected to terminal 6 of the Arduino board to receive signals when there is a change in the setting of the sensors to enable the Microcontroller to send signal to the driver through the base of the transistor Q1 connected to $10 \mathrm{k} \Omega$ resistor to terminal 3 of the microcontroller of the Arduino. At normal conditions, the microcontroller receive normal signal from the temperature and gas sensor. This allows gas from the gas cylinder to flow to the stove burner since the gas tubes are connected through the normally opened (NO) contact of the solenoid valve. When the preset time for cooking is reached, signal from the timer terminal 3 is sent to the Microcontroller terminal 2 to issue a corresponding command to the relay driver to energize the solenoid to close its normally close (NC) contact to prevent flow of gas to the burner thereby turning off fire and simultaneously turning on the buzzer to give an alarm. The status of the cooking is displayed on the LCD under normal and fault conditions. The system is set to its normal condition when cooking is done or a faulty condition is cleared using the reset button. 


\section{RESULT}

The Figure 3 shows how the artifact was assembled, figure 4 shows the test result on the LCD indicating room temperature in degree Celsius, input time in minutes, time remaining in seconds and system time up also indicating. Figure 5 shows the input time during the testing period of the artifact.
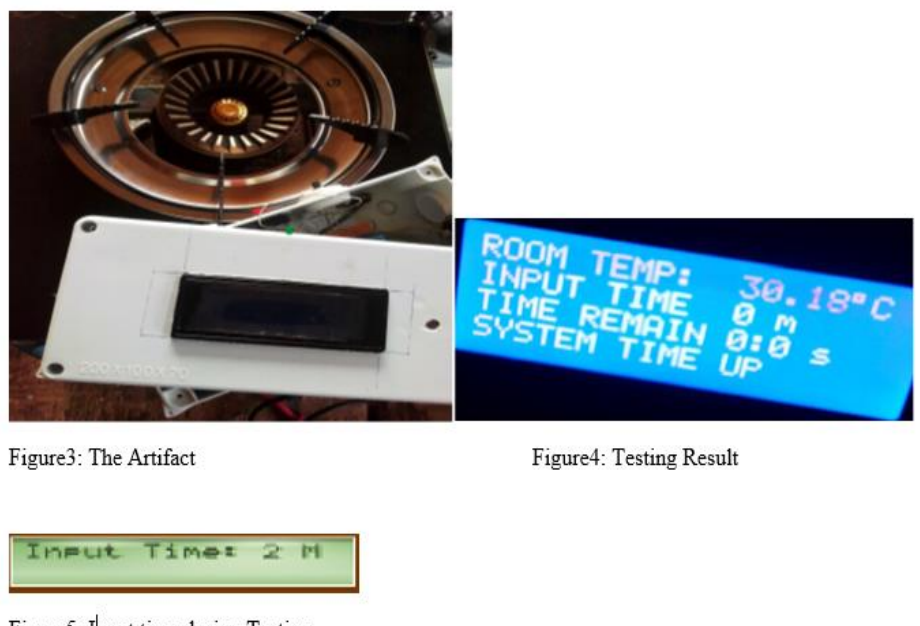

Figure5: Ihput time during Testing

\section{DISCUSSIONS}

When the system is powered, gas flows freely through the pipe to the burner when the solenoid valve is activated. This allows the owner to ignite the burner. After ignition, an input time of 5 minutes is set (time taken for a particular for to cook is set). Two minutes to the set time, the signal is sent to the buzzer to sound an alarm to alert the person cooking to check whether the food is well cooked and if not, an additional time is reset. The temperature (heat) sensor is also set to a particular degree. When the temperature in the cooking environment is above the set degree of the temperature sensor, a signal is sent to the microcontroller to activate an alarm and also closes the solenoid valve to prevent the flow of the gas. Again, when the time set for cooking elapses, power is removed from the solenoid coil which de-energizes the solenoid valve preventing flow of gas to the gas stove burner. This causes the fire coming out of the burner to go off automatically preventing any fire outbreak or food burn when cooking. This system will help reduce or eliminate the loss of lives and properties cause by the gas fire outbreak across the country Ghana and even countries and nations around the globe.

\section{ConClusion}

This paper is aimed at the design and implementation of an intelligent gas cylinder valve regulating to system to regulate gas flow during cooking and also capable of detecting high temperature of the gas cylinder and gas leakage to prevent fire outbreak. The device can detect surrounding temperature and compare to the standard room temperature and any temperature above the threshold setting gives an alarm and shuts-off the gas supply to the burner from the cylinder. An intelligent gas cylinder valve regulating system using solenoid valve was designed and developed. During the testing, it was observed that, different food has their different time interval for it to be cooked. Again, when the surrounding temperature was increased beyond the set point of the sensor using different distances, it was clear that, the longer the distance from the cooking area (cylinder),the longer the response time of the sensor and shorter distance, the sensor respond faster to the gas source. The solenoid valve response fast to signals from the microcontroller when 
International Journal of Computer Science, Engineering and Applications (IJCSEA) Vol.10, No.4, August 2020

time setting elapses to shut-off the solenoid valve. This prototype can be implemented at anywhere cooking is done by using LPG and gas cylinder to reduce or eliminate the chance of occurrences of fire outbreak resulting from mishandling of LPG. This will help facility owners and the government to save money in reconstructions of properties gusted by fire.

\section{REFERENCES}

[1] GNFS, over5000.html.

https://www.modernghana.com/news/908033/ghana-national-fire-service-records

[2] Nadzim N. \& Taib, M. (2014). Appraisal of Fire Safety Management Systems at Educational Buildings EDP Sciences. http://www.shs-conferences.org.

[3] Emmanuel K. A., Tulashie S. K., Joe-Steve A., \& Yeboah I. (2016). Trend of Fire Outbreaks in Ghana and Ways to Prevent These Incidents, Safety and Health at Work. http://dx.doi.org/10.1016/j.shaw.2016.02.004.

[4] Apeh S.T., Erameh K. B. \& Iruansi U. (2014). Design and Development of Kitchen Gas Leakage Detection and Automatic Gas Shut off System. Journal of Emerging Trends in Engineering and Applied Sciences (JETEAS) 5(3):222-228 (ISSN: 2141-7016)

[5] Sagar S., Patil S. B., \& Patil A. J. (2012). Development of Movable Gas Tanker Leakage Detection Using Wireless Sensor Network Based on Embedded System. International Journal of Engineering Research and Applications (IJERA) ISSN: 2248-9622 Vol. 2, Issue 6, pp.1180-1183. www.ijera.com.

[6] Soundarya T., Anchitaalagammai J.V., Deepa P. G., \& Sheela K. S. (2014) Efficient Energy (LPG) Gas Leakage Detection and Prevention System for Home Safety. Artificial intelligence systems and machine learning. Vol 6, No 1. Retrieved from http://ciitresearch.org. on 20/12/19

[7] Geeta L., Rohit B., Lalit D., \& Sachin V. (2017). Design \& Implementation of LPG Gas Detector using GSM Module. International Journal on Emerging Technologies (Special Issue NCETST-2017) 8(1): 98-100(2017). ISSN No. (Online): 2249-3255. www.researchtrend.net.

[8] Murugam, K. (2020). Intelligent gas booking and leakage system using wireless sensor networks. 3C Tecnología. Glosas de innovación aplicadas a la pyme. Edición Especial, Marzo 2020, 273-285. http://doi.org/10.17993/3ctecno.2020.specialissue4.273-285

[9] Padma P. K., Surekha M., Preethi R., Devika T., \& Dhivya N. (2014). Smart gas cylinder using embedded system. International journal of innovative research in electrical, electronics, instrumentation and control engineering. Vol. 2, www.ijireeice.com.

[10] Olubusola O. N., Kamoli A. A., and Ayorinde J. O. (2017). GSM-Based Gas Leakage Detection and Alert System. ABUAD Journal of Engineering Research and Development (AJERD) Volume 1, Issue 1, 100-104. http://ajerd.abuad.edu.ng/.

[11] Folorunso C.O., Raheem W.A., Akinyemi L.A., \& Raji A.A. (2019). Proposed and development of a Liquidified Petroleum Gas Leakage Detector, Level Indicator and Automatic Shutdown System. Covenant Journal of Engineering Technology (CJET) Vol.3 No.2, ISSN: p. 2682-5317 e. 2682-5325.

[12] Rahul G., Shubham M., Salman K., Raghunandan G., and Rahul J. (2018). GSM based gas leakage detection system. International Journal of Advance Research in science and engineering. Volume No.07, ISSN:2319-8354. www.ijarse.com. 